\title{
A dilatometer for measuring the volume changes of concrete under load*
}

\author{
D. C. Spooner
}

\author{
Contribution by A. F. Stock \\ Department of Civil Engineering, University of Surrey
}

I am very interested in the dilatometer method of measuring the volume changes of concrete under load, as described by $\mathrm{Mr}$ Spooner. Although this point is not mentioned in the paper, I believe that measurements made by the dilatometer method include non-uniform strains due to end effects as well as uniform strains in the centre of the specimen. Therefore I am not sure that the volume change of the whole of the specimen is a suitable parameter for studying the problem of the onset of microcracking in concrete under uniaxial compressive stress.

Non-uniform lateral strains have been demonstrated to exist at the ends of specimens of rock by Farrar ${ }^{(1)}$ and of concrete by Newman and Lachance ${ }^{(2)}$. Figure I, taken from reference 2 , compares the lateral strain

*Pages 173 to 176 of $M C R 84$. distribution at approximately $30 \%$ of the ultimate stress in cement paste, mortar and concrete prisms with an aspect ratio of 3 . It shows quite clearly that the concrete specimen is restrained at the specimen-platen interface and then bulges outward before achieving a region of uniform lateral strain towards the centre of the specimen. The bulge is much less pronounced for the mortar specimen and non-existent for the cement paste, but restraint is evident for both these materials.

Would Mr Spooner comment on the possible effect of end conditions upon his measurements, especially with regard to the initial shape of the relationship between stress and volumetric strain? It may be preferable, in studies of the volumetric straining of a specimen under uniaxial compression, to confine measurements to the central portion of a specimen with an aspect ratio of at least $2 \cdot 5$, thus following the generally accepted practice for longitudinal strain measurement.
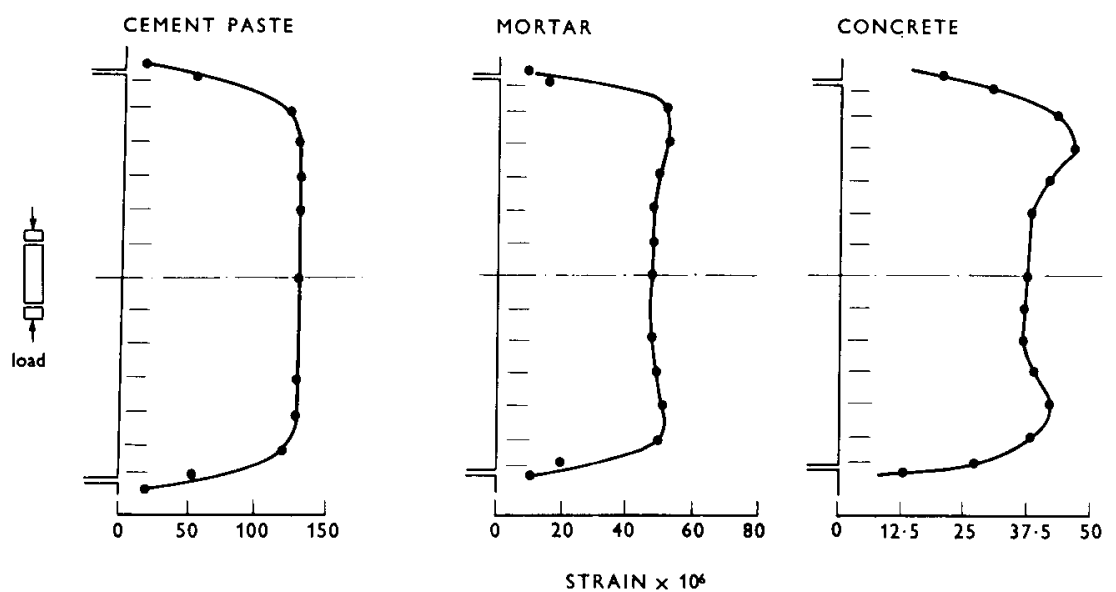

Figure I: Lateral deformation profiles for $102 \times 102 \times 307 \mathrm{~mm}$ prisms (after Newman and Lachance $\left.{ }^{(2)}\right)$. 
Reply by the author

I would like to thank Mr Stock for his contribution to my paper. The dilatometer was designed to measure the volume changes occurring in $75 \times 75 \times 250 \mathrm{~mm}$ prismatic specimens to supplement other work where the energy dissipated into damage was measured in a specimen loaded in uniaxial compression. It is very difficult to know where damage occurs in a specimen during loading and it may not be restricted to the central position of the specimen referred to by $\mathrm{Mr}$ Stock. Consequently measurements of volumetric strain which are restricted to that central region may not provide information which could be correlated with the total damage. Therefore it was thought to be sensible to make volume-change measurements which, like the energy determinations, related to the whole of the specimen.

I have compared the volumetric strains occurring in prisms loaded in uniaxial compression measured by the dilatometer and by the usual surface-mounted, electrical-resistance strain-gauge method. The results are illustrated in Figure II. The agreement is close and any discrepancies at higher stresses can reasonably be attributed to the differences in strength between the specimens. The advantage of the dilatometer over the strain-gauge method is apparent in that it enables

\section{REFERENCES}

1. FARRAR, N. $W$. The influence of platen friction on the fracture of brittle materials. Journal of Materials. Vol. 6, No. 4. December 1971. pp. 889-910.

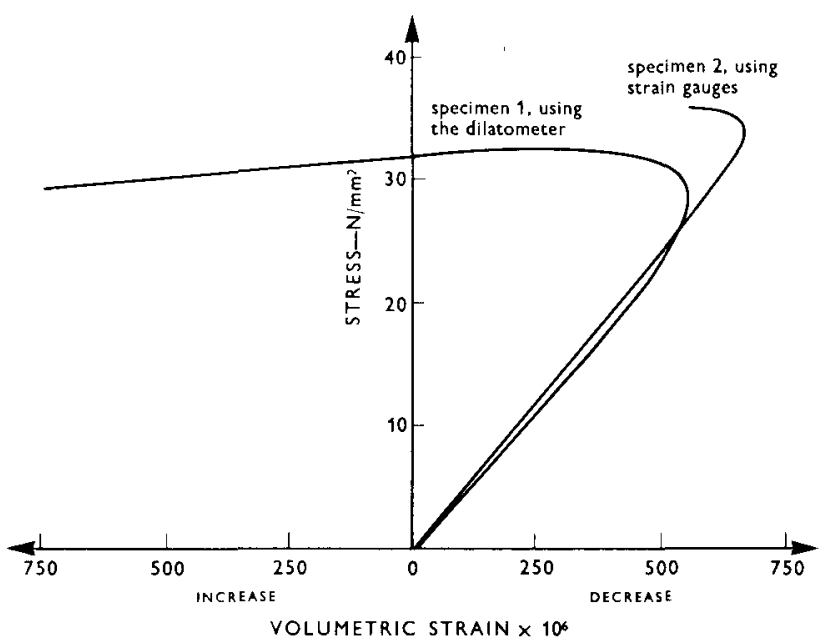

Figure II: Comparison between methods of determining volumetric strain on $75 \times 75 \times 250 \mathrm{~mm}$ prisms.

readings to be obtained well beyond the peak stress. This comparison indicates, therefore, that the nonuniform strains cited by Mr Stock do not introduce significant differences between the two methods of determining volumetric strain when these prismatic specimens are used.

2. NEWMAN, $K$. and LACHANCE, L. The testing of brittle materials under uniform uniaxial compressive stress. Proceedings of the American Society for Testing Materials. Vol. 64. 1964. pp. 1044-1067. 